\title{
Improvement of Health and Safety in Construction Sites in Sri Lanka
}

\author{
W.D. Darshana
}

\begin{abstract}
This research specifically investigated the safety perceptions, attitudes, and behavior of construction workers and the management of safety practices. By analyzing its results, this study demonstrates that a majority of construction companies in Sri Lanka that were considered in the study have very little risk awareness and that they do not consider health and safety as important issues. The aim of this research was to understand from the data gathered and by analyzing the mechanism of injuries, the value of a Health and Safety Policy and prevent preventable accidents and illnesses by ensuring a good reporting system.
\end{abstract}

Keywords: Health and Safety, Improvement of Safety Policy, Construction Sites, Job Safety Check List, Safety Equipment Check List

\section{Introduction}

Construction is one of the most dangerous industries in the world (G.M. Waehrer, 2007, ) and (R. Sacks, 2009)). The ramifications of construction accidents are increasing with a growing trend towards complex projects (H.S. Lee, 2011), especially in developing countries like Sri Lanka. With the boom in the construction industry and with its gross product constantly increasing, the number of construction accidents and deaths has remained stubbornly high. The absolute mortality in the construction industry remains unacceptably high, and the accidents can cause a huge loss of life and property making the construction safety management important (L. Ding, 2014) The measurement and assessment of safety performance is therefore urgent and important in order to improve safety management and prevent accidents .

In the National Institute of Occupational Safety and Health Act, No. 38 of 2009 (b) of Sri Lanka, it is mentioned that the Institute will advise the government on the measures required to prevent accidents and injuries relating to occupations at work places, undertake and assist in investigations and study programs, surveys and research in the field of occupational safety and health.

According to the Department of Labor in Sri Lanka, 500,000 man days are lost annually due to occupational health hazards. There is a limited list of modifiable occupational diseases found in Sri Lanka provided in the Factories Ordinance No.45 of 1942 as amended by Acts No. 54 of 1961 \& No. 12 of 1976. Most of the occupational hazards are not reported as individuals opt to take treatment on their own. According to a survey done, the Accident and Orthopaedic Service of the National Hospital in Sri Lanka has treated 102,321 accidents victims in the year 2015. It is mentioned that $12 \%$ of the injuries to people are due to occupational health hazards. Fifty percent of the fatal accidents are from the construction industry. Most of these hazards and accidents are preventable. As the "legislative protection" is limited to workers in the "factories", there is a need to cover all workers working outside the "factories" as well.

According to the Construction Industry Health and Safety Strategy, 2004-2010, a large number of unskilled and unqualified workers are still engaged in the industry and as a result workplace accidents occur at an unacceptably elevated rate. The contractors and employers are responsible for ensuring the availability of adequate welfare facilities and Personal Protective Equipment (PPE) and for the general health and safety monitoring (executive, 2007).

Older construction workers are considered as an asset and they are perceived to be dedicated, reliable and producing work of a high quality (J. Leaviss, Understanding the Older Worker in Construction, 2008). They receive a high level of respect from their younger colleagues, as they have spent years

Mr.W.D.Darshana, TEng., AIE(Sri Lanka), B.Eng. (Hons) (University of Wolverhampton), AMIIE(Sri Lanka), M.ASCE, Civil Engineer, Researcher at State Engineering Corporation of Sri Lanka.

Email:dushandarshana87@gmail.com 
learning their trade (D.A. Lombardi, Factors influencing worker use of personal protective eyewear, 2009) and are considered to hold trade related skills that are superior to those of their younger counterparts.

However, there has been no research on quantifying these skill levels, which may be due to the recent changes in the levels of qualifications available to construction workers (A.R.J. Dainty, 2005) and (D.A. Lombardi, Factors influencing worker use of personal protective eyewear, 2009). Historically, there are also negative perceptions; older workers are perceived to be difficult to train, slower in their work, and averse to health and safety regulations (e.g. wearing PPE), and these have become concerns for the industry in which time is often considered as money (P.E. Taylor, The ageing workforce: employers' attitudes towards older people, 1994), and (E.Y. Williams, 2011)

The Ministry of Labor in Sri Lanka, which is the primary agency for providing occupational health \& safety services in the country, lacks institutional capacity to address these issues on its own, while the Ministry of Health has to bear the burden of morbidity and mortality caused by occupational hazards. It is the need of the hour to recognize the importance of inter-sectoral collaboration in addressing these issues by developing a national plan of action, and strengthening the institutional mechanisms and analytical facilities to remedy the situation. However, occupational health and safety issues have not been clearly addressed in the National Policy on Health Information developed by the Ministry of Health, Nutrition and Indigenous Medicine (Medicine, 2013).

\subsection{Research Question}

In order to reduce the number and severity of work zone accidents and illnesses, it is important to know the size and scope of the problem. This can be determined through the collection and analysis of work zone safetyrelated data, in collaboration with the Ministry of Labor and the Ministry of Health (Medicine, 2013). There are also no clearly defined regional, institutional or program based focal points for health information management in all the areas. Notably, some disciplines have developed information systems to cater to their individual needs, although there are no proper mechanisms for their integration into the national Health Information System (HIS). Moreover, this lack of integration has led to the repeated capture of the same data by different groups, placing an undue burden on the data collection process. Most data collection forms have not undergone timely revisions. There has been no proper way of collecting data in the work zones in Sri Lanka. Therefore, it is necessary to introduce or establish an institution or a ministry to collect data related to accidents that occur in construction sites in order to reduce this burden and to regularly update the health and safety policy in Sri Lanka. It is doubtful that all companies know this policy. Therefore, the health and safety standards in the construction sites need to be improved by covering general health and safety provisions. Employees in the industries should be required to comply with record keeping regulations and required to submit electronically to the relevant authority, the details about any injury and illness.

\section{$1.2 \quad$ Scope}

As mentioned above, the problems of health and safety in construction sites can be addressed and solved on a national scale as well as on a global scale resulting in improvements that can be observed nationally and globally. Therefore, solutions to health and safety problems applied by one country may readily be adapted to other countries and enable its further improvements. The scope of this research, based on the approved methods adopted in Sri Lanka, was to introduce the foundations on which appropriate health and safety systems could be built in Sri Lanka.

Unfortunately, there is no proper way of collecting data on all the accidents that occur in construction sites in Sri Lanka. These accidents are not reported to the authorities. Therefore, the health and safety standards in construction sites should be improved by covering the general health and safety provisions in these sites as well as the duties and responsibilities of the employers, engineers, contractors, and sub-contractors with regard to safety measures and minimum necessary requirements so that it will ensure that there are satisfactory health and safety standards within their respective organizations. This paper presents the results of a study made on the problems pertaining to health and safety found in construction companies in Sri Lanka and how these could be addressed. 


\section{Literature Review}

In industrialized countries, occupational accidents and illnesses are responsible for 5$7 \%$ of all deaths. According to a report by the International Labor Organization (ILO), approximately 2 million fatal and 268 million non-fatal occupational accidents take place annually (Office, 2003). Furthermore, the ILO estimates that production losses, absenteeism, medical treatments and compensation payments to injured employees would be $4 \%$ of the annual global gross domestic product (J. Takala, 2014). This means that occupational accidents and illnesses have become serious problems in the industries (B. FernandezMuniz, 2012) and (A.A. Ramli, 2011)

'Health' refers to the protection of bodies and minds of people from illnesses resulting from materials, processes or proceedings used in a work place whereas 'safety' is the protection of people from physical injury (N. Holmes, An Exploratory Study of Meanings of Risk, 1999). The (European Foundation for the Improvement of Living and Working Conditions, European Foundation for the Improvement of Living and Working Conditions, , 1991) concluded that about $60 \%$ of the fatal accidents in construction sites arise from decisions made upstream from the construction site.

The study began with a detailed literature review on health and safety in the construction industry focusing on the scope of the construction industry and the activities that involve perilous and dangerous operations. Thereafter, the focus was on analyzing the need to improve health and safety in construction projects taking into account the factors responsible for the major causes of site accidents which result from globalization and cultural issues. Finally, challenges faced by developing countries such as Sri Lanka in implementing effective health and safety procedures was studied.

Safety management includes both preventive and corrective actions required to continuously improve the working environment (Works, 2006) and (P. Oedewald, 2006). Construction work is dynamic and complex. It is inherently dangerous (G. Carter, 2006). But many risks can be avoided through the proper implementation of safe work practices.
Occupational Health and Safety (OHS) laws and standards are based on a technical approach in managing the risks associated with working conditions (N. Holmes, An exploratory study of meanings of risk control for long term and acute effect occupational health and safety risks in small business construction firms, 1999) Poor safety standards and lax enforcement make workers vulnerable to accidents (Watterson, Global construction health and safety-What works, what does not, and why?. Special issue: the international construction industry, January 2007, ).

An 'accident' is defined by the Health and Safety Executive (HSE, 2003) as any unplanned event that results in injury or ill health to people, or damage or loss to property, plant, materials or the environment or a loss of a business opportunity.

According to the National Institute of Occupational Safety and Health Act, No. 38 of 2009, the Health and Safety Executive (HSE) is responsible for enforcing in Sri Lanka the Health and Safety at Work (HSW) Act and in carrying out day-to-day work to enable the National Institute of Occupational Safety and Health to carry out its functions. According to the recent statistics of the Labor Department of Sri Lanka, during the period from 2012-10-01 to 2013-09-30, the numbers of accidents reported by employers was 392. During the same period, the Accident and Orthopedic Service of the National Hospital of Sri Lanka has treated 11,047 patients from among a total of 105,217 patients who have had occupational injuries. This number amounts to a percentage of $10.5 \%$. The 2013 performance report of the Labor Department of Sri Lanka states that only $3.5 \%$ employees have reported accidents. It is clear that there is no proper way of obtaining information about accidents by the relevant authorities in Sri Lanka. On the other hand, the total number of cases arising from occupational hazards that were inquired during the same period was 1970.

\subsection{Construction Sector in Sri Lanka}

According to the Industry Report of Sri Lanka September 2011, the Sri Lankan construction industry is expected to grow at a rapid pace in the post-conflict scenario. The end of the ethnic conflict of the island in 2009 has revived the economic activity and has resulted in a strong focus on infrastructure development. 
The construction industry contributes to about 70 per cent of the Gross Domestic Fixed Capital Formation of the country and about 8 per cent to its GDP which is growing since 2003. The industry ranks seventh among the 13 major sectors contributing to the country's GDP. In 2010, Sri Lanka's construction industry recorded a growth rate of 9.3 per cent as compared to 5.6 per cent in 2009. Its contribution to the GDP was about LKR 423.4 billion, at prices that remained constant. Increased construction activity has also contributed to a 12 per cent annual growth of the building material industry (ltd., 2011)

The acceleration of the ongoing projects such as the development of the power sector including mega projects and road development including expressways and interregional national highways is likely to generate a large demand for construction companies. In 2010, the disbursement of loans for the construction of houses, business premises, other buildings, and property development increased by 39.6 per cent.

The construction industry contributes 7 per cent to employment in the country. In 2009, the direct employment in the construction industry was 562,000 persons. This included four categories of employees: professionals, technical personnel, craftsmen, and machine operators. Almost 97 per cent of the total number of persons employed was males with 75 per cent coming from the 25-45 age-group with 52 per cent having less than 5 years of experience (Ltd., 2011)

\subsection{Accidents Statistics of the Construction Industry in Sri Lanka}

According to the information available at the Labor Department, the statistics related to fatal and non fatal accidents are shown below. Every year, 2,500 - 3,000 accidents have been reported to the Industrial Safety Division of the Labor Department. Out of this number, $40 \%$ to $60 \%$ were fatal and around $30 \%$ were due to construction methods.

\section{Type of Accidents}

Year 20002001200220032004200520062007

$\begin{array}{lllllllll}\text { Fatal } & 16 & 19 & 13 & 13 & 12 & 14 & 15 & 19\end{array}$

Non-Fatal $138123121 \quad 86 \quad 45 \quad 50 \quad 89 \quad 113$

(Source: Department of Labor)

According to these data, most of the fatal accidents had been reported to the Labor Department, but of the non fatal accidents only $50 \%$ to $60 \%$ had been reported. The rest of the construction accidents had not been reported mostly due to the relevant employers and managers in the being not aware of the requirements and the reporting procedures.

\section{Methodology}

\section{Data Collection}

Interviews and questionnaires were developed to collect data. The written questionnaires were delivered mostly by hand and some were delivered by post. The target population of the study included state and private companies. A total of 305 usable questionnaires that were returned by 22 construction companies, were checked and analyzed.

Construction companies were selected as follows randomly:

Three micro companies - work force less than 10

Nine small companies - work force 10- 50

Six middle companies - work force 50- 250

Four large companies - work force over 500

The respondents were upper management (50\%) and middle management (50\%). The upper management respondents comprised senior managers, engineers etc. The middle management respondents were safety personnel comprising safety officers, technical staff like supervisors and site coordinators.

There were two types of questionnaires. One was delivered to the authorities of the construction companies/sites while the other was distributed among the workers of those construction companies. Taking into consideration the pilot study and the findings of the structured interview and literature review, the final questionnaires were carefully designed by the writer to determine the level of application of health and safety in construction sites. In the questionnaire, the respondents were asked to rank the critical causes of accidents and illnesses that were reported. The questionnaire generally categorized four areas, i.e., human causes, accident reporting system causes, time related causes and organizational causes.

\section{Results and Discussion}

\subsection{Question - Response rate by company type}

Twenty two construction companies at different levels were randomly selected to culture of construction. The percentages of 
responses received were 13.60 and 40.90 from micro and small construction companies respectively. The responses from medium and large companies were $22.27 \%$ and $18.18 \%$ respectively.

\subsection{Question - Categories of persons who} filled up the questionnaires

\section{Position of the person who filled out the questionnaire}

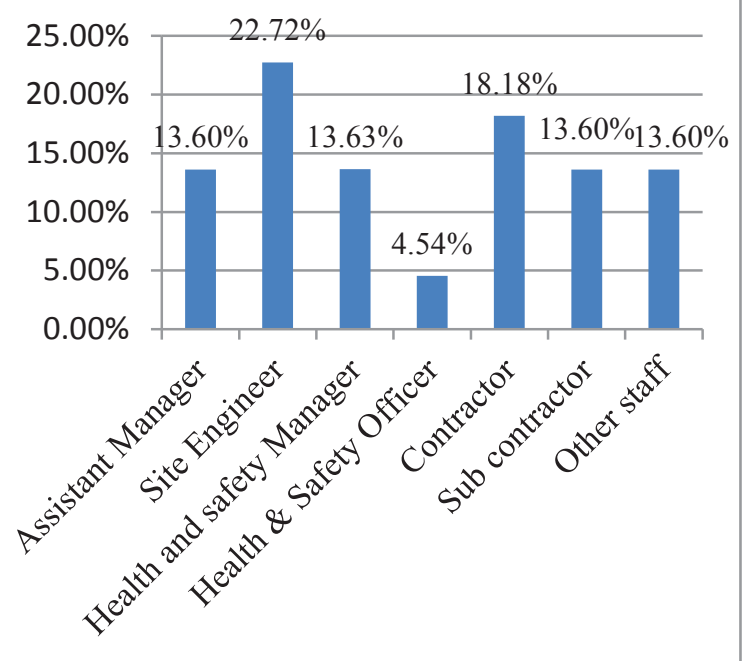

Figure 1 - Categories of Persons who filled up the Questionnaires.

In order to ensure that the responses were reliable and valid, it was important to determine the position of the person who answered the questionnaire. The persons who filled up the questionnaires were Assistant Managers (13.63\%), Site Managers (22.72\%), Health and Safety Managers (13.63\%), Health \& Safety Officers (4.54\%), Contractors $(18.18 \%)$, Sub Contractors $(13.63 \%)$ and other staff $(13.63 \%)$.

Legally, the people who work as health and safety authorities need to have as qualifications at least a Bachelor's Degree in Engineering or in a related field and have to be knowledgeable in construction industry operations, materials and methods. A strong working knowledge of ISO (International Organization for Standardization) 9001:2008: ISO 14001:2004 and OHSAS (Occupational Health and Safety Assessment Series) 18001:2007, COSHH (Control of Substances Hazardous to Health) training certificate etc., (centre, 2015-03-12 ). As Figure 1 indicates, the contractors, sub contractors and other staff who filled up the questionnaire and who together constituted $45.38 \%$ of the total number who responded, did not have even basic qualifications related to health and safety. Others who had filled up the questionnaire were Health and Safety Officers, Health and Safety Managers, Site Engineers and Assistant Managers which comprised $49.95 \%$ of the total number who responded. They have had health and safety training in a different way but that training had not been regular and updated.

\subsection{Question - Health and safety policy, organizations and arrangements}

It is a legal requirement to have a health and safety policy. It ensures the health and safety of the organization's employees and other people affected by the organization's activities.

This question was intended to explore the availability of health and safety policies in construction companies and determine the general content of any policies available in these organizations.

Figure 2 demonstrates that a $68.18 \%$ of the companies which participated in the questionnaire survey did not have a written health and safety policy and that only $31.81 \%$ had a health and a safety policy.

Possession of Health \& Safety Policy in construction companies Percentage

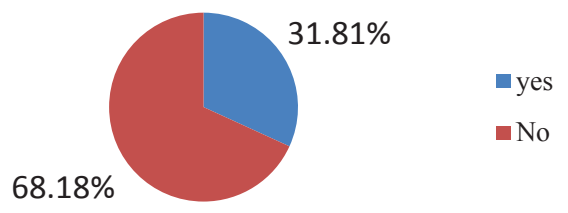

Figure 2 - Availability of Health \& Safety Policies in Construction Companies in Sri Lanka.

In the construction companies in Sri Lanka, there is a serious lack of understanding of the importance of the H\&S policy (DEMOCRATIC, 2009).

Accidents that result in worker injury and death are the effects of poor management of H\&S policies. Therefore, the effective management of H\&S policies is very important in controlling accidents and illness in sites. 
4.4 Question - Has the health and safety policy being updated?

According to Figure 3, 63.63\% of the respondents have stated that their health and safety policies were not updated while $27.27 \%$ have stated that their policies were updated when the working conditions changed. Figure 3 , additionally shows that the remaining $9.1 \%$ of the respondents were not aware of the updating of their health and safety policies.

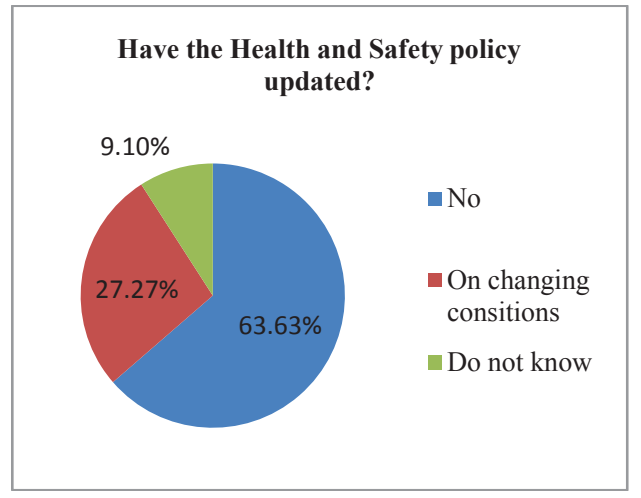

Figure 3 - Updating Progress of Health and Safety Policy.

The health and safety policy is a document required legally and it is one of the key health and safety documents within an organization. It is therefore very important that a company's health and safety policy is up to date and that it is in compliance with current regulations while being relevant to organization's health and safety management procedures. Legally, construction companies are required to update their health and safety policies at least annually. There are also times when a company will need to update their policy earlier, for an example, when there are changes to company work procedures. As the company changes, develops and grows, the health and safety policy of the company need to be updated to address changing risks and safety issues. If the company policy is out of date, it would not comply with the legal requirements, and thus it has to be kept up to date with changes in the company as well as with changes in the law.

\subsection{Question - Consultation of employees on health \& safety}

It is important to make sure that consultation within the organization with employees on health and safety is effectively managed. This question was aimed at determining the attitude of employers towards employee specific health and safety issues by enquiring whether the companies consult their employees on health and safety matters. Out of the participating companies, $40.90 \%$ stated that they consulted their employees on health and safety matters while the remaining 59.09\% replied in the negative. The law requires that employers shall consult the employees on health and safety matters at work. It helps to ensure that H\&S is managed effectively. It requires employers to bring to the attention of their employees any issues or concerns that relate to their health, safety and welfare.

Consultation helps to promote a positive H\&S culture, and ensures that everyone is given an opportunity to influence $H \& S$ policies and procedures.

\subsection{Question - Safety advice received from the company}

It was evident that $31.81 \%$ of the participants received safety advice internally from the company while $68.18 \%$ have not received such advice.

The health and safety professionals must aim to apply current thinking in a practical way to achieve healthier and safer working environments. The IOSH (Institution of Occupational Safety and Health) guide offers several pointers to healthier and safer working conditions by describing some aspects of a good health and safety culture and suggesting some steps that the organizations and their employees can take to improve it.

\subsection{Question - To whom do they report about health \& safety when necessary?}

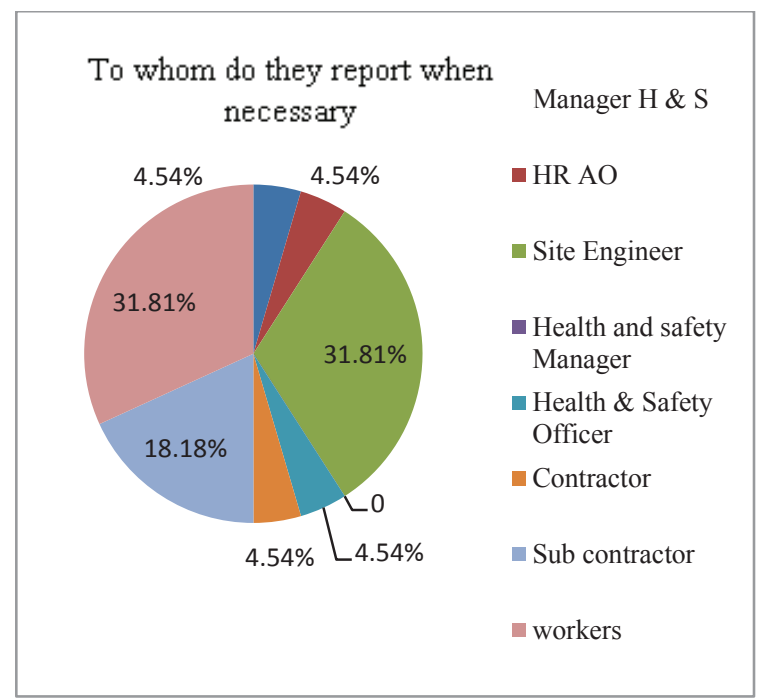

Figure 4 - Reported Persons/Authority about Health and Safety when Necessary.

According to Figure 4, the workers of construction companies knew to whom they 
have to report whenever the need arose. However, during interviewing it was found that this reporting did not happen most of the time. When a hazard happens they take care of themselves without the involvement of their superiors.

\subsection{Question - Health and safety training programs for new employees}

This question was intended to find out if formal health and safety training programs had been provided to the employees by the companies. In response to the question, $90.90 \%$ of the participating companies indicated that they have not had a formal H\&S training program. Regular training on safety through inspection is very essential. This enables the parties involved in a project to be aware of the progress of safe working conditions in the site. The prevention of accidents in construction is largely a matter of education, vigilance and cooperation by everyone involved in the relevant construction projects.

\subsection{Question - Procedures undertaken for risk assessment}

Risk assessment is used to protect workers by identifying the risks in a workplace, controlling them by introducing sensible measures and ensuring that they remain under control. This question was aimed at determining whether the participating companies had procedures for undertaking risk assessments in their workplaces.

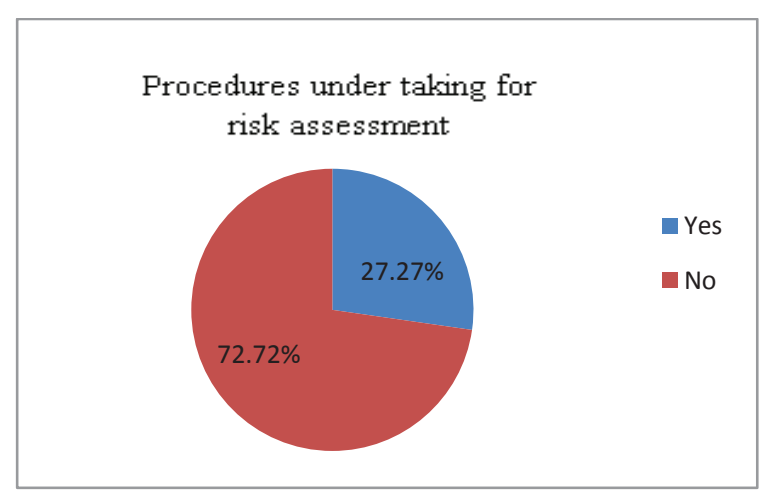

Figure 5 - Procedures for undertaking Risk Assessment.

Figure 5 demonstrates that $72.72 \%$ of the companies did not have procedures for undertaking risk assessments whilst 27.27\% confirmed the existence of such procedures in their companies.

This study established that the training and is inadequate and that therefore there is a need to review same and probably implement a training program on health and safety since all employees have to be given health and safety induction training when they commence work and when risks change, and thereafter refresher training when their skills are not being frequently used.

\subsection{Question - Training of workers on health and safety}

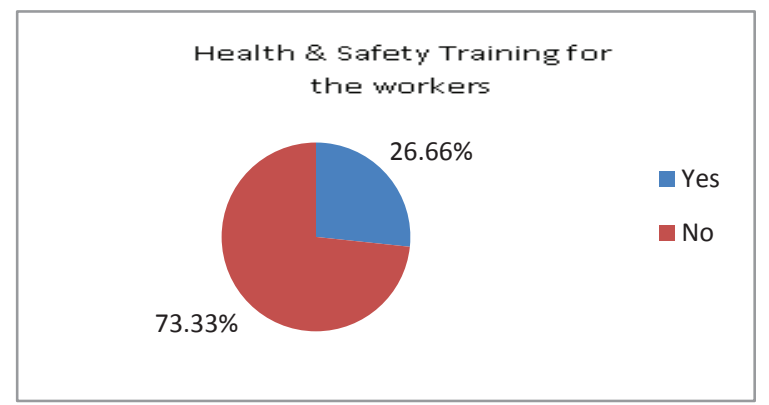

Figure 6 - Training of Workers on Health and Safety.

This question was intended to find out if formal health and safety training programs were provided to the employees by the companies. In response to the question, $73.33 \%$ of the participating companies indicated that they did not have a formal H\&S training program while $26.66 \%$ companies confirmed of having a formal H\&S Training Program. The health and safety training of employees is important to ensure that employees are not injured or made ill by the work they do as well as to develop a positive health and safety culture among them to enable a safe working environment. We found that in Sri Lanka, construction sites are very poor in educating workers on health and safety matters.

\subsection{Question - Types of accidents}

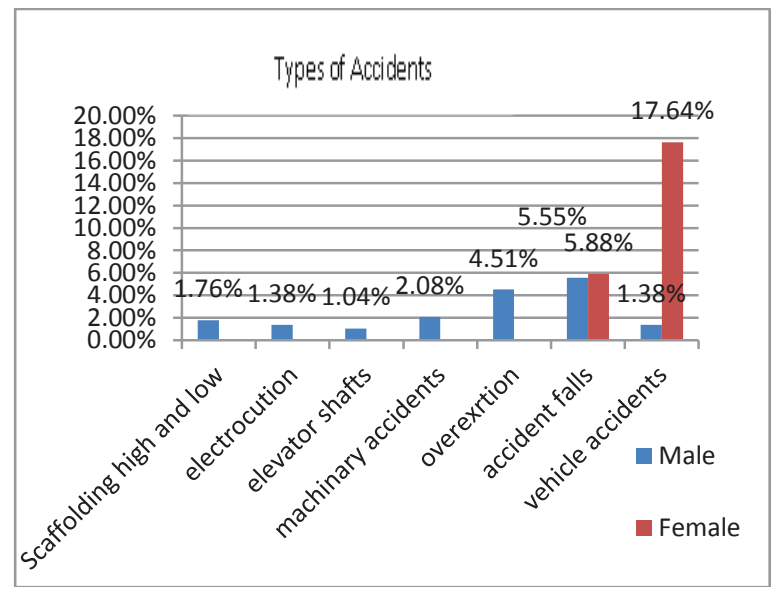

Figure 7 - Types of Accidents. 
Data on occupational accidents are very little and scattered. Under the Factories Ordinance, it is compulsory for all factories to report to the Labor Department all injuries \& diseases caused to workers if the workers do not come to work for 3 days, and to send in returns every six months. However these are hardly reported and proper records are not available, except for few studies done. The reason for this is largely attributable to lack of an institutional mechanism to ensure accountability and to make operational a surveillance system. This tool helps employers to find hazards and fix them up before injuries, or deaths occur.

\subsection{Question - Accident reporting system}

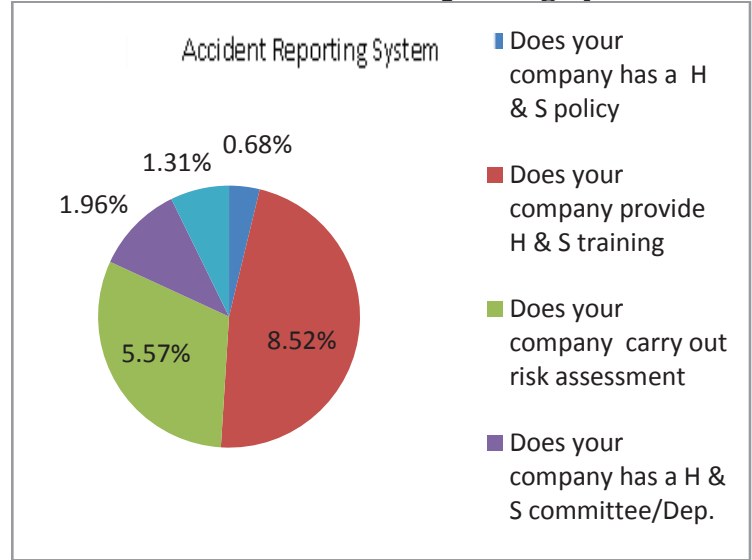

Figure 8 - Accident Reporting System.

When considering the accident reporting systems of construction companies in Sri Lanka, we found that the workers have very little awareness of the availability of such reporting systems. According to Figure 8, only $0.68 \%$ workers knew that they have a health and safety policy and $8.52 \%$ workers have received training on health and safety although such training was not regular and updated. The percentage of companies that carried out risk assessment was only $5.57 \%$. Information regarding the committees on health and safety in the companies was obtained from the interviews. Most of those who responded were not satisfied, probably because they were unaware of these systems.

The H\&S situation in any organization can always be improved if mistakes within the system are noted and actions taken to eliminate the mistakes. Question 4.11 explored whether the information on the accidents reported was utilized to improve the method statement to avoid their recurrence.

\section{Recommendations and the Conclusion \\ 5.1 Framework for Health and Safety Management}

According to the National Institute of Occupational Safety and Health Act, No. 38 of 2009, the Health and Safety Executive (HSE) is responsible for the enforcement of the Health and Safety at Work (HSW) Act and carrying out day-to-day work to enable the National Institute of Occupational Safety and Health to carry out its functions. The OHS is responsible for the promotion of the HSW and encouraging research, training and for the provision of an information and advisory service. The other authorities define an accident more narrowly by excluding events that do not involve injury or ill-health (Lanka, 2011).

Therefore, enforcement mechanisms are a part of health and safety management. An organizational framework must be set up to facilitate the implementation of the policy in all construction companies. A structure that clearly defines the duties and responsibilities at various levels as far as safety is concerned must be developed. It should ensure that safety is integrated into rather than separated from the production activities thereby facilitating a total commitment to safety.

The determination of the extent to which the identified factors contribute to effective health and safety management is based on the following model of risk management (Hinze, 1995)

- Knowing what the risks are, and what in general should be done about them

- Planning, prioritizing and implementing risk controls

- Ensuring that risk controls are effective and sustained

- Reviewing and learning

More specifically, the objectives of the exercise were to collate the opinions from a range of experts regarding the evidence on the features associated with effective health and safety management.

Most of the key elements required for the effective health and safety management are very similar to those required for good quality finance and general business management.

The principles of good and effective management provide a sound basis for the 
improvement of health and safety performance.

By considering the results of the interviews and the questionnaires, the framework shown in Figure 2 consisting of the following five key elements is suggested:

\section{- A clear health and safety policy}

The evidence shows that a sound, well thought out policy contributes to business efficiency and continuous improvement throughout the operation. The involvement of the senior management has to be evident in that all stakeholders take seriously their responsibilities towards people and the environment.

\section{- A well-defined health and safety organization}

The understanding of / concern on the organization's values and beliefs shared among all levels of the company is an essential component of a positive health and safety culture. An effective organization will be noted for good staff involvement and participation; high quality communications; promotion of competency; and empowerment of all employees to make informed contributions.

\section{- A clear health and safety plan}

This involves the setting up and implementing performance standards and procedures through an effective health and safety management system. The plan has to be based on risk assessment methods to decide on priorities and it should set objectives for controlling or eliminating hazards and reducing risks. The measurement of success requires the establishment of performance standards against which achievements can be measured.

\section{- Measurement of health and safety} performance

This includes both active and reactive monitoring to see how effectively the health and safety management system is working. Active monitoring involves looking at the premises, plant and substances, the people, procedures and systems. Reactive monitoring discovers through investigation of accidents and incidents why control has failed. It is also important to measure the organization against its own long term goals and objectives.
- Audit and review of health and safety performance

The results of monitoring and independent audits should be systematically reviewed to see if the management system is achieving the right results. This must be a part of any company's commitment to continuous improvement. Comparisons should be made with internal performance indicators and external performance of organizations with exemplary practices and high standards. The inclusion of health and safety performance in meaningful annual reports is considered to be the best practice.

However, the study established that health and safety committees in construction sites is a key aspect in the enforcement of health and safety but as revealed from this study these committees have not been set up in most construction sites. Factory inspections as required by the Occupational Health and Safety Act (2007) are hardly carried out implying that the enforcement is inadequate. This is further exemplified by the indication that only one of the respondents had been punished for his failure to observe health and safety regulations.

This shows that the enforcement mechanisms of health and safety in construction sites are not adequate. Health and safety audits in construction sites are a key aspect in enforcing health and safety measures; however, a high percentage indicated that they do not carry out audits.

\subsection{Health and Safety Policy in Construction}

According to the data presented in Figure 2 and Figure 3, it is clear that people do not understand the importance of the health and safety policy in construction.

The health and safety policy sets out how health and safety is managed within an organization and demonstrates a commitment to the health and safety of its staff and others.

All employers have a duty to protect their employees and others from any harm that can arise from work activities. The Health and Safety at Work Act 1974 states that all organizations should have a health and safety policy, and that this must be a written policy when they employ five or more people.

The policy should cover all aspects of the organization and should be relevant to the 
employees. It is only required to address health and safety matters relating to employees. However, since employers also have a duty to protect others from risks arising out of their work activities, the best practice would be to consider the safety of people whose health and safety might be affected by the organization, such as volunteers, contractors, the general public etc.

It is important that all employees are aware of and have an understanding of the health and safety policy of the organization and have access to a copy of it. As we know, the H\&S policies (Annexure A) of many major companies in Sri Lanka are not accurate and up to the standard. We found many H\&S policies among large companies and one of them is as follows:

\subsection{How to develop a Health and Safety Policy}

The system should cover the entire gambit of an employer's occupational health and safety system. The key elements of a successful safety and health management system are:

\subsubsection{Policy and Commitment}

Effective safety and health policies should set a clear direction for the organization to follow. They will contribute to all aspects of business performance as part of a demonstrable commitment to continuous improvement. The responsibilities to people and the working environment will be met in a way that fulfils the spirit and the letter of the law. Costeffective approaches to preserving and developing human and physical resources will reduce financial losses and liabilities. In a wider context, stakeholders' expectations, whether they are shareholders, employees or their representatives, customers or society at large, can be met.

\subsubsection{Planning}

The workplace should formulate a plan to fulfill its safety and health policy as set out in the Safety Statement. An effective management structure and arrangements should be put in place for delivering the policy. Safety and health objectives and targets should be set up for all managers and employees.

\subsubsection{Implementation and Operation For the effective implementation, organizations should develop the capabilities and support mechanisms necessary to achieve}

the safety and health policy, objectives and targets. All staff should be motivated and empowered to work safely and to protect their long-term health, not simply to avoid accidents. These arrangements should be:

- underpinned by effective staff involvement and participation through appropriate consultation, use of the safety committee if present and the safety representation system and,

- Sustained by effective communication and promotion of competence, which allows all employees and their representatives to make a responsible and informed contribution to the safety and health effort.

There should be a planned and systematic approach to implementing the safety and health policy through an effective safety and health management system. The aim should be to minimize risks. Risk assessment methods should be used to determine priorities and set up objectives for eliminating hazards and reducing risks. Wherever possible, risks should be eliminated through the selection and design of facilities, equipment and processes. If risks cannot be eliminated altogether, they should at least be minimized by the use of physical controls and safe systems of work or, as a last resort, through the provision of PPE (Personal Protective Equipment). Performance standards should be established and used for measuring the achievements. Specific actions to promote a positive safety and health culture should be identified. There should be a shared common understanding of the organization's vision, values and beliefs on health and safety. The visible and active leadership of senior managers will foster a positive safety and health culture.

\subsubsection{Measuring performance}

The organization should measure, monitor and evaluate the safety and health performance. Performance can be measured against agreed standards to reveal when and where improvement is needed. Active selfmonitoring reveals how effectively the safety and health management system is functioning. Self-monitoring looks at both hardware (premises, plant and substances) and software (people, procedures and systems, including individual behavior and performance). If controls fail, reactive monitoring should find out why they had failed, by investigating the accidents, ill health or incidents, which could 
have caused harm or loss. The objectives of active and reactive monitoring are:

- To determine the immediate causes of substandard performance

- To identify any underlying causes and implications for the design and operation of the safety and health management system.

\subsubsection{Auditing and Reviewing of} Performance

The organization should review and improve its safety and health management system continuously, so that its overall safety and health performance is improved constantly. The organization can learn from relevant experience and apply the lessons. There should be a systematic review of performance based on data from monitoring and from independent audits of the whole safety and health management system. There should be a strong commitment to continuous improvement involving the development of policies, systems and techniques of risk control. Performance should be assessed by:

-internal reference to key performance indicators

-external comparison with the performance of business competitors and best practices in the organization's employment sector

Many companies now report on how well they have performed on worker safety and health in their annual reports and how they have fulfilled their responsibilities with regard to preparing and implementing their Safety Statements. In addition, employers have greater responsibilities that require them to be in a position to prove they have pro-actively managed the safety and health of their workers. Data from this 'Auditing and reviewing performance' process should be used for these purposes.

\subsection{Introduction of Health and Safety Policy in construction industry}

The information and suggestions contained in this Construction Health and Safety Policy have been developed from sources believed to be reliable.

The following safety policy is provided only as a guide to assist employers and employees in complying with the requirements of each construction company, as well as to provide other helpful information. An employer should review the standards for the particular requirements which are applicable to his individual situation and make adjustments to this program that are specific to their company. An employer will need to add information relevant to their particular facility in order to develop an effective and comprehensive program.

\section{OBJECTIVE}

The Safety Policy of Company Name is designed to comply with the Standards of the occupational Safety and Health Administration, and to endeavor to maintain a safe and injury/illness free workplace. These standards shall be available in the home office at all times and shall be sent to the jobsite on request.

Compliance with the following Safety Policy and all items contained therein is mandatory for all employees of the company. The authorization and responsibility for the enforcement has been given primarily to the Responsible Person. The other Responsible Person(s) will also share this responsibility.

II. POLICY It is the company policy that accident and illness prevention shall be a prime concern of all employees. This includes the safety and well being of all employees, subcontractors, and customers, as well as the prevention of wasteful, inefficient operations, and damage to property and equipment.

III. APPLICABILITY This Safety Policy applies to all employees of Company Name, regardless of position within the company. The Safety Rules contained herein apply to all subcontractors and anyone who is in a company project site. Every employee is expected to comply with the Safety Policy, as well as OSHA Health and Safety Standards.

IV. IMPLEMENTATION This Safety Policy supports six fundamental means of maximum employee involvement:

A. Management commitment to safety

B. Weekly tool box safety meetings in all jobsites

C. Effective job safety training for all categories of employees

D. Job hazard analysis provided to all employees

E. Audio and/or visual safety presentations given in jobsites by the Responsible Person

F. Various incentive awards for exemplary safety performance 
The Responsible Persons will meet at least once a month to evaluate all areas of safety and make recommendations to the company head.

V. ADMINISTRATION The Safety Policy will be carried out according to the guidelines established and published in this and other related procedures. Specific instructions and assistance will be provided by the Responsible Person as requested. Each supervisor shall be responsible for meeting all requirements of the Safety Policy, and for maintaining an effective accident and illness prevention effort within his or her area of responsibility. Each supervisor shall also ensure that all accidents are thoroughly investigated and reported to Responsible Person(s) on the day of the occurrence.

VI. REPORTING OF INJURIES AND ILLNESS All employees will be held accountable for filling out a "Notice of Injury Form" immediately after an injury occurs, even if medical treatment is not required. (Notice must be made at or near the time of the injury and on the day of the injury.) Employees must report the injury to their supervisor/foreman/superintendent/project manager/site engineer, etc.

A casual mentioning of the injury will not be sufficient. Employees shall let their supervisor know:
A. How they think they hurt themselves
B. What they were doing at the time
C. With whom they were working at the time
D. When and where it happened
E. Other pertinent information that will assist in the investigation of the incident.

The failure to report an injury immediately (meaning at or near the time of the injury and on the day of the injury) is a violation of the Safety Policy, and may result in immediate termination of service in accordance with the company policy.

\section{NOTIFICATIONS}

A. In case of serious injury or death

After the injured has been taken to the hospital, the foreman/supervisor shall notify the main office and Responsible Person(s) as soon as possible. Statements from witnesses shall be taken. These statements shall be signed by witnesses and should include the time and date. CCTV camera footage or photographs of the area where the incident occurred and any other relevant items are to be taken. The Responsible Person will assist in the investigation. The completed accident report form will be sent to the main office (data analyzing authority).

B. In case of inspection by an OSHA Inspector: The lead man /foreman/supervisor shall notify the Responsible Person(s) that an OSHA Inspector is at the jobsite. It is the responsibility of all employees to make the inspector's visit to the jobsite as pleasant and timely as possible.

\section{BASIC SAFETY RULES}

A. Compliance with applicable county, city, client, and company safety rules and regulations is a condition of employment.

B. All injuries, regardless of how minor they are, shall be reported to your supervisor and the Safety Office immediately. An employee who fails to fill out a "Notice of Injury Form" and send it to the Safety Office can be issued with a safety violation notice and may be subject to termination of service in accordance with the company policy. In the event of an accident involving personal injury or damage to property, all persons involved in whatever way will be required to submit themselves to a drug test.

C. Hard hats shall be worn by all employees in the project site at all times. The bill of the hard hat will be worn in front at all times. Alterations or modifications of the hat or liner are prohibited. Crane operators, when in an enclosed cab, shall have the option of not wearing a hard hat to avoid possible obstruction of view.

D. Safety glasses shall be worn as the minimum-required eye protection at all times. Additional eye and face protection such as mono-goggles and face shields shall be required for operations such as grinding, jack hammering and in utilizing compressed air or handling chemicals, acids and caustics. Burning goggles for cutting, burning or brazing, welding hoods for welding etc. will be required.

E. Fall Protection Requirements

1. Full body harnesses and lanyards shall be worn and secured when there is a fall hazard of more than six (6) feet. 
2. Lifelines shall be erected to provide fall protection where work is required in areas where permanent protection is not in place.

3. Structural steel erectors are required to "hook up" with full body harness and lanyard.

4. Employees using lanyards to access the work or position themselves on a wall or column, etc., shall use an additional safety lanyard for fall protection.

5. Man lifts shall be used properly. As soon as an employee enters an articulating boom lift and before the lift is started, the employee shall put on the harness and attach the lanyard to the lift.

F. Clothing shall provide adequate protection to the body. Shirts shall have at least a tee sleeve. Shirts with sleeves and long pants shall be worn at all times. No shorts shall be worn on projects. All employees, except welders and burners, shall tuck shirt tails inside trousers. Burners and welders will not be permitted to wear polyester or nylon clothing. Sturdy work boots with rigid, slip resistant soles are required. No clogs, tennis shoes or loafers are permitted. Steel-toed tennis shoes with the ANSI (American National Standards Institute) label are the only alternative to the leather work boot.

G. All personnel will be required to attend safety meetings as stipulated by project requirements in order to meet OSHA Safety Standards.

H. Firearms, alcoholic beverages or illegal drugs are not allowed on company property or in company vehicles at any time. When drugs have been prescribed by a physician, the Responsible Person must be informed. The use or possession of illegal drugs or alcoholic beverages in the jobsite will result in immediate termination of service.

I. Housekeeping shall be an integral part of every job. Supervisors \foremen and employees are responsible for keeping their work areas clean and hazard-free. A clean up will be required when finishing a job at the end of the day.

J. Burning and cutting equipment shall be checked daily before being used. Flash back arresters shall be installed at the regulators on both oxygen and LP bottles. All gas shall be shut off and hoses disconnected from bottles and manifolds at the end of the work day. Caps on bottles shall be replaced.
K. All tools whether company or personal shall be in good working condition. Defective tools shall not be used.

L. All extension cords, drop cords, and electrical tools shall be checked, properly grounded with ground fault interrupters, and color-coded by a designated competent person each month. This shall be part of the assured grounding program. Cords and equipment that do not meet requirements shall be immediately tagged and removed from service until repairs have been made.

M. The jobsite speed limit is $10 \mathrm{MPH}$. No employee will be permitted to ride on the bed of a truck standing up or sitting on the outside edges of a truck. Employees shall be sitting down inside the truck or truck bed when the vehicle is in motion. Riding as a passenger on equipment is prohibited unless the equipment has a safe capacity for transporting personnel.

O. Adequate precautions shall be taken to protect employees and equipment from hot work such as welding or burning. Fire extinguishing equipment shall be no further than 50 feet away from all hot work.

P. All scaffolding and work platforms shall be built and maintained in accordance with OSHA specifications. All ladders shall be in a safe condition without broken rungs or split side rails. Damaged ladders shall be removed from service. Ladders shall be secured at the top and bottom and extend three (3) feet past the working surface. Metal ladders around electrical work will be prohibited. A step ladder shall never be used as an extension ladder. A step ladder shall only be used when fully opened with braces locked.

R. All unsafe conditions and near accidents shall be reported to the Responsible Person so that corrective action can be taken.

S. All floor openings or excavations shall be barricaded on all sides to ensure that employees are aware of the hazards. Floor holes shall be covered, with the covers secured and clearly marked.

T. Warning signs, barricades, and tags shall be used to the fullest extent and shall be obeyed. 


\section{U. Scaffold Tag System}

1. Green tags shall be placed on 100 percent complete scaffolds with all braces, locks and hand, mid, and toe rails in place before use.

2. Yellow tags indicate incomplete scaffolds. If scaffold is missing a hand, mid, or toe board, it shall have a yellow tag and employees on it shall be tied off at all times.

3. Red tags indicate scaffolds that are in the process of either being erected or disassembled. These scaffolds shall not be used at any time.

4. Scaffold tags shall be placed in a highly visible location on the scaffolds for all employees to see.

X. All OSHA Safety Standards shall be followed in job processes requiring respiratory protection

Y. All OSHA Safety Standards shall be followed during excavation.

Z. All OSHA Safety Standards concerning confined space entry, lockout/tag out of energized equipment and job processes requiring fall protection shall be followed.

IX. ENFORCEMENT OF THE SAFETY POLICY The safety violation notice(s) will be issued by the Responsible Person to any employee, subcontractor, or anyone else in the jobsite if the safety rules or regulations have been violated.

A. Any violation of safety rules can result in the suspension or immediate termination of services.

B. The services of any employee who has been served with three (3) written general violation notices within a period of six (6) months shall be terminated.

C. The issuance of a safety violation notice upon failure to use fall protection or report a job injury (at the time of the injury) may result in an immediate termination of services of the employees concerned in accordance with the company policy. It is understood that the Company Name is not restricting itself to the above rules and regulations. Additional rules and regulations as required by the job will be issued and posted as needed.

\section{JOB SAFETY CHECKLIST}

The following Job Safety Checklist has been done:

\section{A. Safety Rules}

Hard hats and safety glasses worn.

Shirts with sleeves worn.

Work shoes worn.

Subcontractors' personnel hold

safety meetings as indicated in the project requirements in accordance with OSHA Safety Standards.

Work areas safe and clean.

Safety mono-goggles/face shields

worn when circumstances warrant.

Electrical cords and equipment are properly grounded and checked by a competent person. No evidence of use of alcoholic beverages or controlled substances.

Subcontractors provide fall protection to their employees in accordance with OSHA Safety Standards.

All scaffolds have been built to specifications established by OSHA.

Excavation/trenches sloped or shored as established by OSHA.

Drug testing of employees involved in accident(s) resulting in personal in or property damage.

\section{B. Record Keeping}

Weekly safety meeting sign-in logs maintained in a folder with a copy forwarded to the main office weekly.

\section{Housekeeping and Sanitation}

General neatness.

Regular disposal of trash.

Clear passageways, driveways,

and walkways. Adequate lighting. Oil and grease removed.

used.

Waste containers provided and

Sanitary facilities adequate and clean.

Adequate ventilation.

\section{First Aid}

First aid stations with supplies and equipment. The expiration dates of supplies checked monthly. Expired supplies discarded.

Trained first aid personnel.

Injuries and illnesses promptly and

properly reported.

\section{E. Personal Protective Equipment}

Hard hats.

Hearing protection.

Eye and face protection.

Respiratory protection.

Fall protection. 


\section{F. Fire Protection} identified

Fire extinguishers charged and

No Smoking signs posted.

Flammable and combustible

material storage area.

Fuel containers labeled.

\section{G. Hand and Power Tools}

Tools inspected.

Power tools properly guarded.

Safety guards in place.

\section{H. Welding $\mathcal{E}$ Cutting}

in vertical positions.

Compressed gas cylinders secured Hoses inspected.

Cylinders, caps, valves, couplings, regulators, and hoses free of oil and grease.

place. Caps on cylinders in storage in

Flash back arresters in place.

Welding screens in place.

Fuel and oxygen cylinders

separated in storage.

\section{Electrical}

All portable tools and cords properly grounded

Daily visual inspection of caps, ends and cords for deformed or missing pins, insulation damage and internal damage.

Tests of cords, tools and equipment for continuity and correct attachment of the equipment grounding connector to the proper terminal made every month:

1. Prior to first use.

2. Prior to return to service after repairs.

3. Prior to return to service after an incident that may have caused damage to cord or equipment.

Cords and equipment not meeting requirements immediately tagged and removed from service until repairs are done.

\section{J. Ladders}

Inspected at regular intervals.

No broken or missing rungs or steps.

No broken or split side rail.

Extend at least 36 inches above the landing and secured.

x 6 over 16 feet.

Side rails of $2 \times 4$ up to 16 feet, or 3

\section{K. Scaffolding}

Inspected at regular intervals.
Footings are of a sound ridge and are capable of carrying the maximum intended load. Tied into the building vertically and horizontally at 14 foot intervals.

Properly cross-braced.

Proper guardrails and toe boards.

Scaffold planks capable of

supporting at least four (4) times the maximum intended load.

No unstable objects such as concrete blocks, boxes, etc., used as scaffold foundations.

Use of OSHA Scaffold Tagging

Program.

\section{Guardrails, Handrails and Covers}

Guardrails, handrails and covers installed wherever there is a danger of employees or materials falling through floors, roots or wall openings shall be guarded on all exposed sides.

\section{Material Hoists}

Inspected at regular intervals. Operating rules posted at operators stations.

posted at all stations.

"No Rider" signs prominently All entrances properly protected. All entrance bars and gates painted with diagonal contrasting stripes. Experienced operators.

Current crane certification inspection sticker and papers on the rig.

\section{N. Motor Vehicles}

Lights, brakes, tires, horn, etc., inspected at regular intervals.

No overloaded vehicles.

Trash trucks have covers. truck beds.

No riding on the edge of pickup

No riding on concrete trucks, loaders, backhoes, etc.

Functioning back-up alarms on loaders, tractors, backhoes, etc.

Fire extinguishers installed and readily available.

Seat belts worn at all times.

\section{O. Material Storage and Handling}

Material at least two (2) feet from edge of excavation site.

Proper temperature and moisture levels for safe storage of materials to prevent the deterioration or volatile hazards within the storage area. 
Inventory maintained and inspected frequently.

Proper protective gear worn when handling chemicals.

\section{P. Concrete, Concrete Forms and Shoring}

Full body harnesses as positioning devices for employees tying rebar greater than six (6) feet above adjacent working surfaces Automatic shut-off switches on trowel machines.

No riding on concrete buckets or flying forms.

All forms properly shored.

Single post shores braced $\overline{\text { horizontally. }}$

\section{Q. Use of Cranes and Derricks}

Prohibition of the use of cranes or derricks to hoist employees on a personal platform except in the situation where no safe alternative is possible.

\section{SAFETY EQUIPMENT CHECKLIST}

The following is a list of safety Equipment that should be available on the job, if required, or available from the Responsible Person at all times. Equipment should be checked by the superintendent at intervals in accordance with the applicable OSHA Safety Standards to ensure that all required equipment is present in good condition.

Safety goggles, shields, and glasses

Hearing protection

Respirators

Hard hats

Fire extinguishers (properly

charged)

First aid kit (check list inside kit)

Stretcher or stroke litter (tool room)

Welding masks and goggles

Storage racks for compressed gases

Guards on all power tools

Trash barrels

Company "Safety Policy" packet

posted.

Emergency vehicle (vehicle designated to carry injured to hospital)

\section{SAFETY MEETING REPORT}

A safety meeting report is signed to indicate the attendance of participants. The form has room for employees to sign after attending their weekly safety meeting. This form shall be filled out for each jobsite safety meeting that is held. After the completion of the form, make a copy to be kept in each jobsite and return the signed original copy to the main office.

Safety Meeting

Date:

Topic:

Safety Meeting conducted by

\begin{tabular}{|l|l|l|}
\hline $\begin{array}{l}\text { Employee } \\
\text { Name }\end{array}$ & $\begin{array}{l}\text { Employee } \\
\text { Signature }\end{array}$ & $\begin{array}{l}\text { Job } \\
\text { Title }\end{array}$ \\
\hline & & \\
\hline & & \\
\hline & & \\
\hline & & \\
\hline & & \\
\hline & & \\
\hline & & \\
\hline & & \\
\hline & & \\
\hline & & \\
\hline
\end{tabular}

\section{Acknowledgment}

I state that I have attended the safety orientation, and have read and received a copy of the Company Name safety rules and regulations. I further state that I understand these rules and acknowledge that compliance with safety rules and regulations is a condition of my employment. I understand that I will be subject to termination of my services in accordance with company policy if I violate the safety rules or fail to report an injury to my supervisor immediately.

EMPLOYEE SIGNATURE

DATE

\section{RESPONSIBLE PERSON SIGNATURE}

DATE

The information and suggestions contained herein have been developed from sources believed to be reliable.

\section{References}

1. G. M. Waehrer, X. D. T. M. E. H. Y. M., 2007, Costs of Occupational Injuries in Construction in the United States. Accid. Anal. Prev.,, 39 (6)(25).

2. R. Sacks, O. R. Y. R., 2009. Spatial and Temporal Exposure to Safety Hazards in Construction. J. Constr. Eng. Manage., , 135 (8)(15 July 2009), p. pp. 726-736 
3. H.-S. Lee, K.-P. L. M. P. Y. B. S. L., 2011. RfidBased Real-Time Locating System for Construction Safety Management. J. Comput. Civil Eng., Volume 26 (3), p. pp. 366-377.

4. L. Ding, L. Z. X. W. M. S. Y. Q., 2014. Safety Management in Tunnel Construction: Case Study of Wuhan Metro Construction in China. Safety Science, 62(21 August 2013), p. pp. 8-15.

5. Executive, H. a. S., 2007. Health and Safety. Summary of duties under the CDM Regulations, 08 October, p. 1 to 2.

6. J. Leaviss, A. G. P. B., 2008. Understanding the Older Worker in Construction. 2008) [Online] Available at: http://www.sparc.ac.uk/media/downloads/executive summaries/exec_summary_gibb.pdf , p. [accessed 10.12.12.].

7. D.A. Lombardi, S. V. M. B. M. P., 2009. Factors Influencing Worker Use of Personal Protective Eyewear. Accid. Anal. Prev, 41(2009.03.017), p. pp. 755-762.

8. A.R.J. Dainty, S. I. G. B., 2005. The Construction Labor Market Skills Crisis: the Perspective of Small-Medium-Sized Firms. Constr. Manag. Econ., 23 (4)(2005), p. pp. 387-398.

9. E.Y. Williams, A. G. D. G. R. H., 2011. Constructive Ageing: A Survey of Workers in the Construction Industry. Proceedings of $C I B$ W099 International Conference, 24th-28th August, Washingon D.C., USA.

10. Medicine, M. o. H. a. I., 2013. ANNUAL HEALTH BULLETIN, Colombo: Medical Statistics Unit.

11. A.A. Ramli, J. W. W. P., 2011. Possibilistic Regression Analysis of Influential Factors for Occupational Health and Safety Management Systems. Saf. Sci., 49(2011), p. pp. 1110-1117.

12. Fernandez-Muniz, J. M.-P. C. V.-O., 2012. and Attitudes of Certified Firms. J. Clean. Prod., Volume, 24, p. pp. 36-47.

13. Occupational Risk Management Under the OHSAS 18001 Standard: Analysis of Perceptions Office, I. L., 2003. Safety in Numbers: Pointers for the Global Safety at Work. International Labor Office, Geneva, Switzerland, Issue (2003).

14. N. Holmes, H. L. Z. Y. F. D. M., 1999. An Exploratory Study of Meanings of Risk. Journal of Safety Research, Vol. 30, No. 4, (1999), p. pp. 251-261.
15. G. Carter, S. S., 2006. Safety Hazard Identification on Construction Projects. Journal of Construction Engineering and Management, 132 (2)(01 February 2006), p. 197-205. March 2007), p. pp. 1258-1266.

16. Watterson, A., January 2007,. Global Construction Health and Safety - What Works, What does not, and why?. International Journal of Occupational and Environmental Health, Volume 13(2008), pp. Pages 1-4.

17. Lanka, N. I. o. o. S. a. H. .., 2011. National Institute of Occupational Safety and Health. National Institute of occupational Safety and Health annual report 2011.

18. Ltd., I. M. C. s., 2011. Industry Report on Sri Lanka. Construction, p. 1.

19. Ltd., I. m. C. S., 2011. SWOT Analysis of Sri Lanka. Construction, p. 3.

20. Centre, G. i., 2015-03-12 . Occupational Health \& Safety Management in Sri Lanka.. Training Programmes offered by SLSI.

21. DEMOCRATIC, P. O. T., 2009. NATIONAL INSTITUTE OF OCCUPATIONAL. NATIONAL INSTITUTE OF OCCUPATIONAL, No. 38 ([Certified on 23rd July, 2009]), p. Part II of the Gazette of the Democratic.

22. P. Oedewald, T. R., 2006. Safety Critical Organizations. VTT Publications, , Issue 2006. P.E. Taylor, A. W., (1994),. The ageing

\section{Annexure A}

\section{An Existing Safety Policy in Sri Lanka}

We, at ......... Construction (Pvt) Ltd., are a team committed to provide quality products and services at an affordable price and on time, in the execution of construction projects and in the manufacture of related products, with the support of our valuable suppliers and in total harmony with the society and the environment.

We are further committed to satisfy our customers whilst improving the quality of life of our people thereby improving the viability of our organization. We value team work, efficiency, responsibility and responsiveness to achieve these goals, through the optimization of resources and continual improvements of our systems at all levels of operations to further enhance the quality of our products \& services. 


\section{Environmental Policy}

Construction (Pvt) Ltd is one of the leading construction companies and RMC manufactures of Sri Lanka. We fully understand the severity of the pollution generated by construction and RMC manufacturing processes and therefore e are fully committed to reduce all significant environmental impacts resulting from our activities, products and services by incorporating recycle, recover and reuse options to provide a better, cleaner and safer environment for sustainable development. To achieve our goals we are making our best efforts towards the successful establishment, implementation and maintenance of an Environmental Management System (EMS) according to International Standard ISO 14001:2004.

We are committed to:

- Comply with all the legal and other requirements to which ........ Construction (Pvt) Ltd subscribes.

- Continually improve the Environmental Management System by regularly monitoring and reviewing of our objectives, targets and programs.

- Provide training to our workforce and staff on a regular basis as and when required for the improvement of their professional skills and attitudes towards ensuring the effective implementation of the EMS.

- Communicate our environmental policy at all levels i.e. internally as well as externally and to the general public or any other interested parties whenever they ask for it.

\section{Health \& Safety (H\&S) Policy}

The effective implementation of integrated management systems is the core of our business strategy.

- We at ............ Construction (Pvt.) Ltd. is working as a team to make our customer to prefer our works and services and to retain our position as the leading supplier of engineering works and services.

We are sensitive to the changes of our customer needs including the demands for EW\&S and are bringing continual improvement in our management systems and employees' skills to satisfy those needs.
- We are also determined to provide safe and secure working conditions to our employees to prevent injury, ill health and/or other incidents and are adopting all appropriate measures for the prevention of pollution to our environment and neighbors

- We recognize and are committed to comply with all applicable Sri-Lankan legislation to provide \& maintain safe, healthy and comfortable work environments to our staff, subcontractors, suppliers, customers, visitors \& neighbors.

Copyright (ㅇ 2015 ......... Construction (Pvt) Ltd. All rights reserved. Designed \& Developed by Rapid Venture 